\title{
How Effective are Students' Self-Editing Endeavours? - Evidence from L2 Writing Tasks
}

\author{
D. Kasule, V.B. Lunga \\ University of Botswana, Botswana
}

\begin{abstract}
Assessment in many cases in higher education involves essay writing and the submission of one draft only. Such assessment presupposes that students can self-edit effectively before submitting the essay. This article reports the self-editing endeavours of ten students in two writing tasks. Instruction in self-editing did not minimize errors in both tasks each student submitted. Since self-editing involves all the deliberate efforts of a responsible active agent in text creation, we attribute this result to the novice writers' failure to position themselves as knowledge creators; or as participants; and coresearchers. Although writing instruction helps in eventually producing self-editing writers, we suggest that writing skills be taught as discipline-specific discourse practices rather than as autonomous skills. We recommend that the role of additional error feedback mechanisms namely peers, the lecturer, and the computer be increased and that assessment be more reflective of writing as a process whenever possible.
\end{abstract}

\section{Introduction}

A system of student assessment that focuses solely on the final draft of the essay and the submission of one draft only [53], as is the case at our university, places very high demands on students. They must be able to self-edit their work before they submit it for evaluation so as to score well. The essay is preferred by university administrators over alternative assessment, such as multiple-choice questions which carries limited demands on students' writing skills, because it tests conceptual understanding. [39]. It has thus become an entrenched assessment tool, which also serves a critical gate-keeping role that powerfully excludes those incapable of essay writing [53]. One assumption content lecturers may hold is that over the course of their education, every university student has received sufficient formative feedback [16] on earlier work to have learnt what constitutes correctness, and can therefore self-edit their texts. Students want to write close to error-free texts [40] and so, they adopt coping strategies that may include acts of dishonesty such as recycling essays from former students. Also popular with students, is hiring a commercial typist in town to type their assignments. Alternatively, many enter language support courses such as our Advanced Writing Skills course with the expectations of becoming more proficient writers. However, because the system requires students to submit, not multiple drafts, but only one final draft of the essay, that single submission must be as error-free as possible in order to score well. Such practice misleads students into thinking that writing is a once-off endeavour with no chance to improve if they have made errors of any kind [53]. Additionally, the formative role of teacher feedback which ought to develop students' writing seems non-existent.

Given the above concerns, this article reports the self-editing endeavours of ten (10) university students in two writing tasks. The students were viewed as capable of making the deliberate efforts of a responsible active agent in text creation and so, able to independently act on textual inaccuracies in the content, organization, and mechanics. The term we used for this range of abilities is self-editing. It differs from 'selfmonitoring' a technique where students write marginal annotations about problems in their evolving compositions, to which the teacher responds [8]. So as to understand the extent to which students take responsibility for textual accuracy, we were interested in their ability and effort to self-edit after receiving a number of consciousness-raising lecture-room activities in self-editing.

\section{Studies of L2 writing}

Studies of the writing skills of L2 learners have received much attention from different perspectives. The full range of these perspectives 
includes studies that have addressed whether learners benefit from conscious reflection on grammatical patterns; and the effectiveness of different kinds of teacher feedback, of peerresponse, of self-correction, of open-ended and closed-ended tasks, of the degree of focus on specific error patterns, and of the development of audience awareness [14]. Perhaps the perspective that has received the most research effort is teacher feedback $[12 ; 19 ; 22 ; 23 ; 25 ; 30 ; 35 ; 47$; 52]. Findings are inconclusive on the question whether teacher's error-feedback makes a difference to students' writing; and for the past ten years the controversy has been characterized as the Truscott-Ferris debate. One side of the debate claims that error-feedback in L2 writing is counter-productive and that it has not improved students' writing, instead it had detrimental effects on learners' writing development [46; 47]. Confounding research evidence has been provided to show that fossilization will not occur when these errors are not corrected; adding that error-correction discourages writing [18]. The opposing views argue that error-feedback can improve language accuracy over a period of time [12]. Other studies show written feedback to be effective when it is much more narrowly focused and is directed at specific grammatical features [10] and that it is effective when it is coupled with individual conferencing to explain the teacher's feedback to each student [52], though problematic in large classes such as ours. Such controversy not only reflects the writing teachers' concern about L2 writing, but also portrays as problematic essay assessment based on a single final draft as it is doubtful from research evidence that students can produce error-free texts even with feedback.

Do L2 writers revise their texts? One study reported that compared to L1 writers, L2 writers revise their work at a superficial level; they reread and reflect less on their written text, revise less, and when they do, the revision is primarily focused on grammatical correction; and may not be able to make changes intuitively based on what sounds good [43]. However, the editing and correction strategies of young bilingual children were studied and it was reported that 'even young child learners are able to apply metacognitive strategies to language tasks, without extensive tutoring and scaffolding of the task by a teacher' [13]. Another study examined whether ESL students edit for sentence-level errors and reported that students' level of accuracy improved from draft to revised essay
[42]. Elsewhere, studies used the self-monitoring technique and found that in this way writers learnt to pay greater attention to textual content and organization [8; 9; 54]. Although 'no learner intentionally writes strings of incoherent text' [55], we do not know the extent to which university students come to rely independently on their own abilities to act on the errors in their texts via self-editing even though many writing manuals mention self-editing, and the internet is replete with checklists for achieving this.

\section{The subjects}

This study involved ten ESL second-year students taking the optional Advanced Writing Skills course. They came from a range of learning backgrounds with regard to study experiences at university. Therefore some of the students may have been without a strong essay writing background. For this paper, course of study, age, gender, and home language were not analyzed even though these variables may have a bearing on one's ability to self-edit in an L2. Instead, it was argued that in this way we would minimize the implied cause/effect relationship between these variables and self-editing. Secondly, since assessment procedures in this generic course disregard these variables, the subjects had to undergo homogeneous experiences. Thirdly, as university level students they had reached the stage of language acquisition dependent on attitude, emotional state, and perception of the need for learning English. They had also received all their education in English prior to coming to the university which had also introduced them to the basic conventions of academic writing in English. Additionally, to qualify for university admission, they had fulfilled the stringent entry requirements including a pass in English language examination at grade C (60-69\%) or better for 'non-science-based programs', and grade E (40-49\%) or better for 'science-based programs' [48]. In our view therefore, they formed a very academically motivated group.

\section{Procedure}

In one hour, the students wrote one expository paragraph titled "A Good Student" as TASK 1 whose focus was textual organization. Each student received a typed outline of the content of the paragraph (see Appendix). To organize the outline into a paragraph, the writer 
needed a command of English sentence structure including coordination, subordination, sequencing skills, knowledge of coherence devices, and basic mechanics. For this reason, in a series of preceding lectures the students were introduced to a range of common words and phrases that link ideas in a text to achieve different results, for example:

- To show result: therefore, consequently, as a consequence, accordingly, as a result, for this reason, in that case, due to, etc.

- To show example: for example, for instance, such as, namely, etc.

- To show contrast: but, although, still, yet, even so, however, nevertheless, all the same, in spite of, despite, the contrary, in contrast, etc.

- To show addition: and, also, as well as, moreover, furthermore, in addition to, additionally, etc.

- To show reason: therefore, thus, for this reason, because, since, due to, owing to, that is why, etc.

- To show end: finally, in the end, to sum up, etc.

- To show clarification: in other words, incidentally, alternatively, that is to say, etc.

- To show purpose: in order to, so as to, so that, to, etc.

- To show sequence: then, afterwards, next, after, at last, lastly, one/first/secondly, etc.

They were also shown how the writer's opinion can be expressed by words and phrases such as: in my opinion, surprisingly/to my surprise, in fact, frankly/to be frank, un/fortunately, of course, seriously, quite likely, strictly/strictly speaking, generally/generally speaking, personally, apparently, admittedly, etc. After writing, students were instructed to devote at least ten minutes to using a self-editing tool. The paragraphs were then collected for marking and returned with feedback before TASK 2 was given.

TASK 2 was a take-home task completed over three weeks. Students had to produce a four or five-paragraph essay (typed or handwritten) from the following topics:

- Should smoking be banned in public places?

- Discuss the advantage and disadvantage of a United States of Africa
- $\quad$ Discuss the concept of globalization in the context of your country

- The advantages and disadvantages of technology

- The role of agriculture in the your country's economy and

- Critically examine the characteristics of an effective leader.

During the three weeks they were free to conference individually with the lecturer regarding the content and organization of their developing essay. As a motivator, we made the essay a component of Continuous Assessment (CA).

\section{The self-editing tool}

We set out to work with the students to develop a tool that they were to use to identify errors that may occur in their evolving texts in both tasks. To develop the self-editing tool, students brainstormed in groups to recall lecturers' comments on previously marked scripts. The brainstorming indicated the following errors to be recurrent: sentence fragments, run-on sentence, subject-verb agreement, pronoun reference, parallelism, mixed structures, and misuse of the comma. Although these are only a few of the types of errors that are possible, we decided that they were sufficient for initiating a consciousness for self-editing. After explaining each error using examples from students' scripts, each student was given the typed list below titled "What to look for while self-editing your essay":

- Spelling

- Omissions and repetitions

- Sentence fragments

- Run-on sentences

- Subject-verb agreement

- $\quad$ Pronoun reference agreement

- Parallelism

- Mixed structures

- Misuse of the comma in place of and/but/or/so/Transitions

\section{Findings}

\subsection{Students' self-editing endeavours in Task 1}

Findings from the single paragraph which was written in class indicated that on the whole the guidelines on self-editing minimized only the occurrence of surface errors such as spelling and 
punctuation errors. There were however persistent subject-verb agreement (SVA) errors. Three of the ten essays had this identical SVA problem: 'Good student have a very good habits'. This may be attributed to the fact that the outline was typed. From our experience with students, typed communication has an elevated status in students' view and enjoys unquestioned correctness hence in their typed point form; the contents were accepted as grammatically wellformed. Also equally prevalent were problems in combining sentences to create cohesion and conciseness, perhaps attributable to the lack of time since the paragraph had to be submitted at the end of the one-hour lecture.

Another problem was poor sequencing of the writer's thoughts. In one of the samples what began as general guidelines (A good student is one who...) abruptly became instructions of what a good student ought to do (Review notes after class. Start early on an assignment). Another sample exhibited problems with the basic structure of a paragraph because the writer merely reproduced the ideas in the outline separated by full stops and capital letters. The result was a string of strange 'sentences' that had no subject: 'Presents notes in a specific format that is easy and clear to read e.g. date, page, numbers and information. Uses a pencil or different ink for definations [sic] or questions. Visits lecturer in the office' etc. [After typing it out verbatim, Microsoft Office Word 2007 through "Word Help' identified the problem and rightly recommended the following: "If the marked words are an incomplete thought, consider developing this thought into a complete sentence by adding a subject or a verb or combining this text with another sentence"]. This recommendation would have helped the writer tremendously had it been typed. Our expectation had been that following the lectures on self-editing, this short paragraph would have been largely error-free. In virtually all ten scripts, neither the self-editing tool nor the instruction were evidently helpful.

\subsection{Students' self-editing endeavours in Task 2}

We analyzed the ten essays for errors that, in our opinion, were identifiable on the basis of the self-editing tool and ignored other error types. Error counts such as this one are however problematic because writers may deliberately minimize errors not by self-editing, but by keeping their text short or by avoiding those structures they know to cause them difficulty. For purposes of this study, however, it was rather fortunate that the ten essays exhibited the folly of many L2 student writers that long essays score higher, no matter what their content! For that reason, instead of a maximum of five paragraphs, two students produced twelve and eleven typed paragraphs respectively, while another produced ten handwritten ones. There was one who saw nothing wrong with using font 14 and a bulleted format for some paragraphs while others are indented. Although exceeding the limit did not constitute an error, the manipulation that goes with forcing essays to become long confirms the students' misunderstood purpose of academic writing. The others, including those that had sections lifted verbatim from the internet, had paragraphs that were short, disjointed, and poorly demarcated from each other just to create textual length, albeit only visually. On the subject of using the internet, one essay had wellformed paragraphs but the contents were not the 'writer's' own. So instead of the internet being used to enrich the writer's thoughts, it was used to cheat. Although it may not be possible to establish a cause/effect relationship between the lack of self-editing and error occurrence, what tended to occur consistently was that by focusing on essay length, the writers increased the errors in their work because either the writers failed to identify the error or failed to correct the error after identifying it. This poor performance is strong evidence against the current assessment process that focuses solely on the final draft of the essay We had assumed that, for a three-week take-home writing task involving lecture activities dealing with self-editing; an opportunity for individual conferencing with the lecturer; and the task contributing to one's CA, effort would be made to self-edit.

Table 1 below summarizes the analysis. Our assumption that the students in this study had been 'empowered' to determine correctness was not borne out by what they wrote in the essay. As in TASK 1, in virtually all ten scripts, neither the self-editing tool nor the instruction helped.

Table 1. Incidences of errors in students' essays

Sample A: Topic: Globalization [6 short
handwritten paragraphs]
(i) Paragraphs lacked distinct topic sentences e.g.
a 3-sentence paragraph beginning with
exploitative diamond pricing globally ends with
pollution of the environment 'as people move
around and some copy other cultures leading to




\begin{tabular}{|l|}
\hline cultural decay' \\
\hline Sample B: Topic: Leadership [10 short \\
handwritten paragraphs] \\
(i)Error in $1^{\text {st }}$ sentence: A leader is someone who \\
lead the group, can either be a club, or even \\
society. $1^{\text {st }}$ sentence of para 2 is a fragment: \\
According to Ricky whose view is that a good \\
leader is a person who can be trusted. (ii)Mixed \\
structures: (1) This displays that a person have \\
confident in others that they could/can do the job \\
delegated to them.(2) A good leader, at times, \\
he/she need to sacrifice their personal comforts. \\
(3) People appreciate a leader who can admit \\
his/her mistakes but if keep making mistakes all \\
the time people lose faith in your competence. (4) \\
Humility another quality of a good leader but this \\
quality is rare amongst.
\end{tabular}

Sample C: Topic: Leadership [6 handwritten paragraphs]

(i)Parallelism: Honesty and trustworthy... (ii)Mixed structure: (1) In contrary, Redmond argues... (2) In conclusion characteristics of a good and effective leader amongst others include trustworthy, he must be loyal and trusted to lead the team.

\section{Sample D: Topic: Smoking [5 very long} handwritten paragraphs]

(i)SVA error in $1^{\text {st }}$ sentence: Cigarettes contains a substance called tobacco.

Sample E: Topic: Smoking [5 handwritten paragraphs]

Evidently lifted from the internet (hence the minimal errors).

\section{Sample F: Topic: Technology [11 typed} paragraphs]

(i)Mixed structure: According to Chan argues that... (ii)Omission: A live example would of First National Bank (iii)Misleading the reader due to pronoun misuse: These [who?] have received more market attraction

(iv)Misleading the reader e.g. (1) saying the next author contests the first, when in actual fact they concur (2) using the words 'the following' when no list follows

Sample G: Topic: Globalization [12 short poorly demarcated typed paragraphs]

(i) Run-on sentence: To address the twelve critical areas of concern highlighted by Beijing platform for action which [this country] chose six critical areas for development of action oriented strategies to remove gender inequalities and four of them were; women and poverty including economic empowerment, women power-sharing and decision making, violence against women and human rights and the protection of the girl child following the Beijing declaration prioritization process. (ii)Sentence fragment: Violence against women including their human rights remaining as a problem (iii)Several spelling errors: 'man issue' instead of 'main issue'; 'be default' instead of 'by default'; 'raises a print' instead of 'raises a point'; etc.
Sample H: Topic: Smoking [8 typed (font 14) paragraphs some bulleted others indented]

Minimal errors because it is lifted and sources unacknowledged

Sample I: Topic: A United States of Africa [7 disjointed typed paragraphs]

(i)Run-on sentences e.g. (1) This is piece of writing will address what the entire continent of Africa is likely to benefit from a united states and how it can be a disadvantage in relation to issues and conflicts affecting the continent (2) It will bring to an end tribalism which was brought by European's post colony which resulted in Africans who mixed with Europeans genetically looked down on African Africans hence the Hutu, Tutsi genocide, Somalia war, Sudan's Darfur war.(3) some of the poorest countries may then be helped like Sudan, Somalia, Swaziland, Zimbabwe, who resist help from humanitarian organizations and other African states, as she suspects them of being in alliance with postcolonial countries. (ii)Meaninglessness phrases: European's post colony; post-colonial countries; there will be technocratic erasure of the political; already some nations know where that are perceived to fall in that scale; etc

Sample J: Topic: Agriculture ([8 well-formed paragraphs]

Run-on sentence: in commercial farms people are employed as machinery operators, accountants, the BMC also employ a relatively large number of people.

\section{Discussion}

The error-count in Table 1 indicates that students' awareness of the importance of selfediting was neither sufficiently triggered by lecture discussions nor by the activity of Task 1 . There are three possible explanations for this. Firstly, students perceive the lecturer as the model of correctness and their dependency is reinforced by the lecturers' feedback, albeit summative, that rewards correct use of the conventions of linguistic and other textual features. This perception is advanced by the genre approach to literacy based on systemic functional grammar [21] in which texts are shown to be conventionalized according to contextual appropriateness. Unfortunately, the ideal model remains obscure to L2 students; a problem for which it was proposed to teach by writing along with the students so that through modeling, students would recognize the linguistic and textual features to copy [17]. However, from a poststructuralist interpretation of writing, such modeling may fail to produce writers who are independent and empowered. 
Secondly, in TASK 1 the students seemed to have interpreted the content provided in the paragraph outline as received knowledge over which they felt they had very little control. Similarly, in TASK 2, because the topics were chosen for them, students' genuine interest in wanting to talk was minimal. They did not position themselves as creators of new knowledge or as co-researchers [38], hence the plagiarizing of internet sources (Sample D, E, G, I in Table 1) and lecture notes (Sample $\mathrm{H}$ and I). They did not use the essay as a means of actively participating in constructing new knowledge. This may be explained by the fact that traditionally education positions students as subordinate, always on the receiving end, a 'banking' notion of education [15]. The practice where students assume a subordinate role encourages them to “... regurgitate knowledge that is deemed essential in a format that is sanctioned by their discipline" [20].

Thirdly, students viewed the purpose of TASK 1 and TASK 2 as mere evaluative tools that determined pass or failure and writing them was only an act of fulfilling a course requirement. This view was perpetuated by the absence of a real audience beyond the lecturers who chose the topic(s). In their desire to score high marks, textual length had to be manipulated in the different ways evidenced above; and although feedback on TASK 1 should have improved performance in TASK 2, student attention was focused solely on the mismatch between the length of their essay and the low mark it earned.

\section{The theory and practice of self- editing in $\mathbf{L} 2$ writing}

In our view, developing proficiency in selfediting can be theorized as a process of apprenticeship in the ways of academic writing within a given discourse community. In this theorization, the lecturer has a role different from that of evaluator, final judge, or gate-keeper; and academic writing is viewed as a process of social participation or interaction in which the student is positioned as an active agent in text creation, rather than simply as an act of fulfilling a course requirement. Within this apprenticeship process of social participation the lecturer, among other factors, plays a key role of encouraging access and participation in the given community of practice. It is essential to allow and increase opportunities for newcomers to gain "access to a wide range of ongoing activity, old timers, and other members of the community; and to information, resources, and opportunities for participation" [31]. Within such a situatedlearning approach to skill acquisition, teacher feedback may be viewed as part of the process of apprenticing learners into legitimate participation. Additionally, effective writing also results from quality feedback that "the writer receives, whether from self, peers, tutors in a writing center, or a writing instructor" [41]. Unlike contexts that focus on assessing only the finished essay, the importance of feedback is acknowledged in process-based classrooms, where it forms a key element of the students' growing control over composing skills [23]. In other words, self-editors are the product of feedback mechanisms around them. And when student writers position themselves as communicators in a discourse community (consisting of their peers, their lecturer, and themselves), they become their own first readers of the texts they produce.

Self-editors therefore become aware of the literacy practices of a given discourse community through social and cultural participation and interaction. This is because literacy practices, specifically reading and writing, "only make sense when situated in the context of.... and cultural. practices of which they are but a part" [3]. Self-editing demands more than just knowledge of grammar, and requires an understanding of how literacy practices are "bound up with the workings of a particular social institution" [36]. This means that assessment that focuses solely on the final single draft of the essay presupposes that such understanding has occurred; and that the essay benefited from formative feedback, which, "like all acts of communication, occurs in particular cultural, institutional and personal contexts, between people enacting and negotiating particular social identities and relationships, and is mediated by various types of delivery" [24].

Evidence from this current study regarding the inaccuracies in organization, paragraphing, grammar, and content itself, indicates that teaching the conventions of academic writing still has a place in L2 writing classrooms. From the perspective of L1 writing, conventions of writing have been criticized as 'domesticating and limiting because they discourage subjectivity' [38]. However, the important question McIntosh raises for L2 writing instruction is 'what do students benefit, as writers, from a genre approach to literacy'? We are convinced that self-editing, possible only 
through direct instruction, would benefit our students and that knowledge of the conventions helps in eventually producing independent L2 writers who self-edit confidently in order to communicate effectively in writing. From a socio-cultural perspective, knowing the conventions makes student writers members of a community of writing practitioners and that knowledge sets 'the professional apart from the amateur' [45]. Without these conventions they become potential failures, positioned forever in a deficit perspective of $\mathrm{L} 2$ writers where their writing is viewed 'as developmentally weak and their texts as riddled with errors' [50].

However, because contextual realities play a big role in pedagogical practices, the practice of assessing a single final essay draft is not intentional. To begin with, our Advanced Writing Skills course is over-subscribed which creates classroom organizational problems and excessive marking loads. So, while some writers are now referring to a post-process period in L1 contexts [2; 37], the practice in our context tends to remain product-focused. The assessable intervening activities in essay-writing that would enhance the development of self-editing skills, such as outlining and drafting, cannot be included in the teaching due to time, reduced from three to two contact hours per week due to semesterization. Due to heavy mark loads, writing tasks in a semester are minimal in number for purposes of maintaining a complete CA profile of each student, and not because the student requires such a number for practice; and feedback is late since marked scripts are returned long after submission. Often students do not even collect these marked scripts discouraging lecturers who provide quality feedback. Students who collect their scripts make little use of the feedback partly because it lacks relevance to future assignments [16], but mainly because they are only curious to see the grade.

We recommended that writing and reading be understood as processes that often occur together; a view not easily conveyed by the genre approach alone. This is a changed classroom interaction model from what studies of L2 classrooms $(27 ; 29 ; 32$ ] are reporting that it is always the teacher who decides the writing topic and how it should be discussed, and that the students' role is limited to producing a text for evaluation. Our suggestion is to create prewriting tasks that involve everyone but through alternative linguistic modes of participation; for example, to have lecture-room activities involving pre-reading around the topic, followed by discussing/debating, genuine listening, and genuine note-making and summarizing before writing an essay requiring argumentation. Such activities develop increased self-editing practices as the writer holds a genuine interest in what is being communicated to the reader. Additionally, an awareness of academic writing styles and conventions as conveyed via a genre approach is needed to reduce the chance of the writing processes resulting in recurrent frustration. This is the approach that may be characterized as ' $a$ pedagogy that facilitates and hastens linguistic proficiency development, familiarizes students with the requirements and conventions of academic discourse and supports the use of critical thinking and higher order cognitive processes' [30]. Such familiarization arises from legitimate participation in 'real life tasks and functional projects of students, in collaboration among themselves and with mentoring by disciplinary specialists, help produce written texts that make a valid contribution to knowledge' [6].

Regrettably, another contextual problem is that students trivialize courses intended to develop their academic literacy skills but are not directly linked with their major field of study [11]. Students also tend to overrate their competence in English. This contributes to the indifference exhibited in their writing rendering their written texts very tedious to read due to problematic sentence structure and often a complete lack of adequate punctuation. Thus thinking in some circles in higher education has proposed that writing instruction be replaced entirely by computer. However, since the demands of university writing involve much more than the mechanical matters relating to accuracy in spelling, punctuation, and grammar, the computer can do very little. For instance, the writer must supply the essay content such as description, argumentation, thesis statement, focus, factual and experiential information, etc, which the computer cannot do. The writer must also deal with essay organization including the logical development of ideas and arguments, the effectiveness of the introduction and conclusion, and the sequencing of ideas in order of importance. The computer therefore can only supplement the writer's self-editing efforts.

\section{Conclusion}

The paper has argued that assessment of written texts that is not preceded by students' gradual understanding of academic writing as a 
process of communication involving a genuine desire to convey personal thoughts to a real discourse community of interested readers, may not be justifiable. Even explicit self-editing skill instruction becomes ineffective without such understanding. Contextual constraints notwithstanding, in our view self-editing is central to learner-centred pedagogy that can be facilitated by L2 writing perspectives which place the student as an active agent in knowledge creation.

\section{References}

[1] Anderson, J.R. The architecture of cognition. Mahwah, N.J: Lawrence Erlbaum, 1996.

[2] Atkinson, D. L2 writing in the post-process era: Introduction. Journal of Second Language Writing 12(1), 2003, pp. 3-15.

[3] Barton, D., Hamilton, M., \& Ivanic, R. (eds.). Situated Literacies: Reading and Writing in Context. London: Routledge. 2000.

[4] Berthoff, Ann. The making of meaning. Upper Montclair, NJ: Boynton-Cook. 1981.

[5] Bitchener, J. \& Basturkmen, H. Perceptions of the difficulties of postgraduate L2 thesis students writing the discussion section. Journal of English for Academic Purposes 5, 2006, pp. 4-18.

[6] Canagarajah, S. Multilingual writers and the academic community: towards a critical relationship. Journal of English for Academic Purposes. 1, 2002, pp. 29-44.

[7] Carson, J. G., \& Nelson, G. L., Chinese students' perceptions of ESL peer response group interaction. Journal of Second Language Writing, 5(1), 1996, pp. 1-19.

[8] Charles, M. Responding to problems in written English using a student self-monitoring technique. ELT Journal 44 (4) l, 1990, pp. 286 - 293.

[9] Cresswell, A. Self-monitoring in student writing: developing learner responsibility. ELT Journal 54 (3) 2000, pp 235-244.

[10] Ellis, R., Sheen, Y., Murakami, M, \& Takashima, $H$. The effects of focused an unfocused written corrective feedback in an English as a foreign language context. System 36, 2008, pp. 353-371.

[11] Fandrych, I. Socio-pragmatic and cultural aspects of teaching English for academic purposes in Lesotho. Southern African Linguistics and Applied Language Studies 2, 2003, pp. 14-27.
[12] Ferris, D.R. (1999). The case for grammar correction in L2 writing classes: A response to Truscott (1996). Journal of Second Language Writing 8:1-10.

[13] Francis, N. Literacy, second language learning and the development of metalinguistic awareness: a study of bilingual children's perceptions of focus on form. Linguistics and Education 13(3), 2002, pp. 373 -404 .

[14] Francis, N. Bilingual children's writing: self correction and revision of written narratives in Spanish and Nahuatl. Linguistics and Education 16, 2005, pp. $74-92$.

[15] Freire, P. Pedagogy of the oppressed. NY: Continuum Books, 1993.

[16] Glover, \& Brown Written Feedback for Students: too much, too detailed or too incomprehensible to be effective? BEE-j Volume 7: May 2006, http://www.bioscience.heacademy.ac.uk/journal/vol7/ beej-7-3 Accessed 2 June 2009.

[17] Graves, D., A fresh look at writing. Heinneman: Portsmouth, 1994.

[18] Gray R. Grammar Correction in ESL/EFL Writing Classes May Not Be Effective. 2004. The Internet TESL Journal, Accessed 2 May 2005.

[19] Guenette, D. Is feedback pedagogically correct?: Research design issues in studies of feedback on writing, Journal of Second Language Writing 16 (1), 2007, pp. 40-53.

[20] Halasek, K. A pedagogy of possibility: Bakhtinian perspectives on composition studies. Carbondale, Illinois: Southern Illinois University Press. 1999.

[21] Halliday, M. A. K. An introduction to functional grammar. London: Arnold. 1994.

[22] Hedgecock, J. \& Lefkowitz, N. Feedback on feedback: Assessing learner receptivity in teacher response in L2 composing. Journal of Second Language Writing 3 (2), 1994, pp. 141-163.

[23] Hyland, F. Focusing on form: student engagement with teacher feedback. System 31(2) 2003, pp. 217-230.

[24] Hyland, K. \& Hyland, F. Feedback in Second Language Writing: Contexts and Issues. NY: CUP. 2006.

[25] Ibrahim, N. Feedback on ESL writing: Can we integrate form? Dissertation Abstracts International, 63 (5), 2002, pp. 1812A. 
[26] Kamler, B. The writing workshop as a space for relocating the personal. Accessed 16 Oct 2008) http://www.acal.edu.au/publications/papers/occasional /barb arak.html. n.d.

[27] Kasanga, L.A. Learners' belief systems and writing instruction. Journal for Language Teaching, 10, 2006, pp. 139-162.

[28] Kasper, L F. New technologies, new literacies: focus discipline research and ESL learning communities. LLT Journal 4 (2), September 2000, pp. 105-128.

[29] Kasule D and McDonald, R. Teacher practices and verbal interaction in primary schools in Botswana. Language Matters 37, 2006, pp. 16-43.

[30] Kepner, C.G. An experiment in the relationship of types of written feedback in the development of second-language writing skills. Modern Language Journal, 75, 1991, pp. 305-313.

[31] Lave, J. \& Wenger, E. Situated learning: Legitimate peripheral participation. Cambridge: CUP. 1999.

[32] Le Roux, D. The quality of pupil participation in ESL classrooms: an evaluation. Unpublished MA dissertation. Potchefstroom: University of Potchefstroom. 1996.

[33] Le Roux, J. The concept of 'ubuntu': Africa's most important contribution to multicultural education? Multicultural Teaching, 18(2), 2000, pp. 43-46.

[34] Lee, G. and Schallert, D. l. Meeting in the margins: effects of the teacher-student relationship on revision processes of EFL college students taking a composition course. Journal of Second Language Writing 17, 2008, pp. 165-182.

[35] Lee, I., Student reaction to teacher feedback in two Hong Kong secondary classrooms. Journal of Second Language Writing 17 (3), 2008, pp. 144-164.

[36] Lillis, T. Student writing: Access, regulation and desire. Routledge: London and New York. 2001.

[37] Matsuda, P.K. Process and post-process: a discursive history. Journal of Second Language Writing 12 (1), 2003, pp. 65-83.

[38] McIntosh, S. A critical writing pedagogy: Who benefits? Queensland Journal of Educational Research, 17 (2), 2001, pp. 152-163.

[39] Miller R., Bradbury J, \& Lemmon, G. Justifying means with ends: assessment and academic performance. South African Journal of Higher Education 14 (1), 2000, pp. 166-173.
[40] Myles, J. Second language writing and research: The writing process and error analysis in student texts. Teaching English as a Second or Foreign Language 6(2), 2002, pp. 1-20.

[41] Nelson, G. \& Carson, J Cultural issues in peer response: Revisiting 'culture.' In Hyland, K. \& Hyland, F. (eds.). Feedback in Second Language Writing: Contexts and Issues. New York: Cambridge University Press, 2006, pp. 42-59.

[42] Polio, C., Fleck, C., \& Leder, N. "If I only had more time:” ESL learners' changes in linguistic accuracy on essay revisions. Journal of Second Language Writing. 7 (1), 1998, pp. $43-68$.

[43] Silva, T. Toward an understanding of the distinct nature of L2 writing: the ESL research and its implications. TESOL Quarterly 27(4), 1993, pp. 657677.

[44] Stewart, D. C. Composition Textbooks and the Assault on Tradition. College Composition and Communication, 29, 1978, pp. 171- 180

[45] Street, B. Academic literacies and the 'new orders': implications for research and practice in student writing in higher education. Learning and Teaching in the Social Sciences 1(1), 2004, pp. 9-20 The Internet TESL Journal Accessed 2 May 2008.

[46] Truscott, J. (1996). The case against grammar correction in L2 writing classes. Language Learning 46:327-369.

[47] Truscott, J. (1999). The case for "the case grammar correction in L2 writing classes": A response to Ferris. Journal of Second Language Writing 8: 111122.

[48] University of Botswana Calendar 2003-2004. University of Botswana.

[49] University of Botswana. Learning and Teaching Policy. 2008. Accesed on 6 March 2009 from http://tirisano/Shared\%20Documents/Forms/AllItems. aspx.

[50] Vollmer, G. Sociocultural perspectives on second language writing. ERIC/CLL News Bulletin 25 (2), 2006, pp. 1-2.

[51] Williams, J.G. Providing feedback on ESL students' writing assignments. The Internet TESL Journal, 9 (10) 2003. Retrieved $3^{\text {rd }}$ October 2008.

[52] Williams, J.G. Providing feedback on ESL students' written assignments. The Internet TESL Journal Vol. IX (10), 2003. http://iteslj.org/Techniques/Williams-Feedback.html. 
[53] Wright, J. Reflections on process writing. Journal for Language Teaching 40(2), 2006, pp. 88108.

[54] Xiang, W. Encouraging self-monitoring in writing by Chinese students. ELT Journal 58(3) 2004, pp. 238-246.

[55] Yates, R., \& Kenkel, J. Responding to sentencelevel errors in writing. Journal of Second Language Writing, 11, 2002, pp. 29-47.

\section{APPENDIX}

\section{Using the following outline, write one} paragraph titled "A Good Student”

A good student

(i) good study habits

(ii) note-taking during reading + in class

(iii) specific format for note-taking notes are clear + readable e.g. date, page numbers, space for definitions, questions, additional information

(iv) pencil or different ink for definitions or questions - easy to spot during review

(v) review notes after each class i.e. when material still fresh

(vi) visit the lecturer in the office to ask questions - chance to understand the material fully

(vii) start early on an assignment: brainstorm, research, ask the lecturer questions,

(viii) starting early - time to draft, revise, edit; writing improved 